\title{
Characterization of forage fish and invertebrates in the Northwestern Hawaiian Islands using fatty acid signatures: species and ecological groups
}

\author{
Jacinthe Piché $^{1, *}$, Sara J. Iverson ${ }^{1}$, Frank A. Parrish ${ }^{2}$, Robert Dollar ${ }^{2}$ \\ ${ }^{1}$ Department of Biology, Dalhousie University, Halifax, Nova Scotia B3H 4J1, Canada \\ ${ }^{2}$ Pacific Island Fisheries Science Center, NOAA, 2570 Dole Street, Honolulu, Hawaii 96822, USA
}

\begin{abstract}
The fat content and fatty acid (FA) composition of 100 species of fishes and invertebrates $(\mathrm{n}=2190)$ that are potential key forage species of the critically endangered monk seal in the Northwestern Hawaiian Islands were determined. For analysis, these species were classified into 47 groups based on a range of shared factors such as taxonomy, diet, ecological subsystem, habitat, and commercial interest. Hierarchical cluster and discriminant analyses of the 47 groups using 15 major FAs revealed that groups of species with similar FA composition associated into 5 functional groups: herbivores, planktivores, carnivores (which also included piscivores and omnivores), crustaceans, and cephalopods. Discriminant analyses performed on the 4 main functional groups separately revealed that herbivores, planktivores, and crustaceans could be readily differentiated on the basis of their FA signatures, with $97.7,87.2$, and $81.5 \%$ of individuals correctly classified, respectively. Classification success was lower within the carnivores $(75.5 \%)$, which indicates that some groups of carnivorous species likely exhibit highly similar diets and/or ecology, rendering their FA signatures harder to differentiate. Despite a relatively broad overlap, most groups were reasonably well classified (>75\% success). Five groups had $<60 \%$ classification success; these taxa were better explained by separately considering individual factors such as species, diet, or ecology rather than the full range of shared factors. The agreement of the FA signatures with ecologically based groupings indicates they can be used to characterize the fish and invertebrate community in this highly complex subtropical ecosystem. These data provide crucial information on the distinctions and overlaps in the diets of reef fish and invertebrates.
\end{abstract}

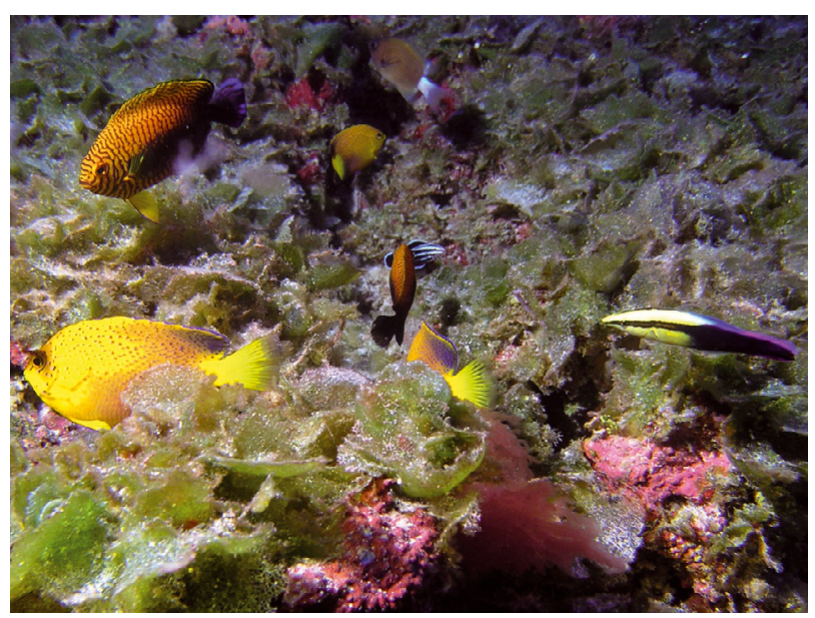

Reef fish on a bank summit of the Northwestern Hawaiian Islands

Image: Raymond Boland

KEY WORDS: Fatty acids $\cdot$ Fishes $\cdot$ Invertebrates $\cdot$ Diet guild · Trophic relationships · Ecological subsystems · Hawaiian archipelago • Northwestern Hawaiian Islands - Monk seal

Resale or republication not permitted without written consent of the publisher

\section{INTRODUCTION}

Marine ecosystems are complex and diverse, and understanding the trophic interactions and energy flow through them is a tremendous challenge (Steele 1996). Increasingly, bottom-up and top-down impacts on predator and prey populations are evaluated to understand species distributions, population dynam- 
ics, and ecosystem structure and change. Traditional methods to study aspects of predator-prey relationships and marine food webs have relied on prey remains recovered from predator stomachs and feces. However, newer methods such as biochemical tracers and DNA analyses have emerged as a means to determine such relationships (Deagle et al. 2005). One of the most promising of these approaches is the use of fatty acids (FAs) to study food web structure and potentially to estimate the types and proportion of prey consumed by a predator (reviewed by Dalsgaard et al. 2003, Iverson et al. 2004, Budge et al. 2006, Iverson 2009). Given the diversity of FAs in marine ecosystems and their conservation through food chains, FAs can be used to gain a powerful understanding of trophic interactions within ecosystems (e.g. Budge et al. 2002, Iverson et al. 2002, Parrish et al. 2002, Dalsgaard et al. 2003, Dalsgaard \& St John 2004, Stowasser et al. 2009).

Most recently, FA signature analysis has been advanced to quantitatively estimate diets of higher predators such as seabirds and mammals (quantitative FA signature analysis, QFASA; Iverson et al. 2004, 2006, 2007, Beck et al. 2007, Nordstrom et al. 2008, Thiemann et al. 2008, Tucker et al. 2009). These diet estimations have been conducted in northern temperate to Arctic ecosystems (and/or in captivity) using a small (3 to 9) to relatively moderate $(\leq 28)$ number of prey types. However, in more highly complex food webs, multiple prey species thriving in the same habitat and feeding on similar resources may become more difficult to differentiate based on FA signature alone. Additionally, statistical problems arise when the number of potential prey increases and numerically exceeds the number of FAs used in the QFASA estimation procedures.

Coral reefs are the largest biological features on earth and support more species per unit area than any other marine ecosystem (Wood 1999). The Northwestern Hawaiian Islands (NWHI) ecosystem $\left(25\right.$ to $30^{\circ} \mathrm{N}$, $175^{\circ} \mathrm{E}$ to $165^{\circ} \mathrm{W}$ ) constitutes the most remote largescale coral reef ecosystem in the world (Maragos \& Gulko 2002), with its 10 atolls and islets extending $2000 \mathrm{~km}$ northwest of the main Hawaiian islands (MHI). The subtropical communities of this region vary with the depth and habitat found on the upper slopes of the Hawaiian ridge. The peaks support coral reefs or banks of algal meadows. In contrast, the flanks of the ridge experience less photosynthesis and grow little biotic substrate where the slopes extend into the abyss. Because of its vertical nature, the trophic structure of the NWHI is extremely diverse and unique, with an overall fish biomass in the shallow reefs of $2.4 \mathrm{t} \mathrm{ha}^{-1}$, comprised of $27 \%$ herbivores, $18 \%$ low-level carnivores, and dominated (54\%) by apex predators (Friedlander \& DeMartini 2002). The diversity and biomass of fish communities subsequently diminishes with depth to levels as low as $0.0035 \mathrm{t} \mathrm{ha}^{-1}$ in the subphotic (301-500 m) zone (Parrish \& Abernathy 2006). A key top predator in the NWHI ecosystem is the Hawaiian monk seal Monachus schauinslandi, which is the only non-migratory phocid seal relying entirely on subtropical insular ecosystems for subsistence (Ragen \& Lavigne 1999). Monk seal populations have experienced severe declines over the past several decades and are listed as critically endangered. Thus, understanding their foraging ecology and the prey species upon which they depend is a central issue in assessing management and recovery plans. However, estimating their diet using FA signatures is problematic as they inhabit an extremely diverse ecosystem comprising a multitude of potential prey species.

Thus, the NWHI represents an ideal platform to investigate the use of FA signatures as a tool to reveal trophic relationships in an extremely complex and tropical ecosystem. To use FAs to understand trophic interactions both among forage species, and also eventually at the top of the food web in the NWHI, it is necessary to first characterize FA patterns and their variation in the prey assemblage. Given the great diversity of potential prey species in the NWHI, a critical step for eventual quantitative predator analysis must be to reduce the vast number of species into ecologically relevant groups. The objectives of this study were to (1) determine the FA composition of NWHI fish and invertebrate species that are potential prey of the Hawaiian monk seal, (2) explore meaningful ways to collapse a high number of representative prey species into relevant groups that are biologically and ecologically meaningful to allow the largest number of species to be incorporated in trophic analyses, and (3) determine to what degree these species/groups of species can be characterized on the basis of their FA signatures.

\section{MATERIALS AND METHODS}

Sample collection. A collection program was established as part of a study of the diet of the Hawaiian monk seal at the NOAA Pacific Islands Fisheries Science Center. Fish and invertebrate species were sampled across the eastern end of the NWHI archipelago from 1997 through 2005. The bulk of specimens were collected from 4 main islands/reef areas: Necker Island, French Frigate Shoals (FFS), Gardner Pinnacles, and Maro Reef (see Table S1 in the supplement at www.int-res.com/articles/suppl/m418p001_supp.pdf). Over $85 \%$ of the total samples originated from these 4 locations, and more than $50 \%$ of those were collected at FFS. Reasons for concentrating collection effort at FFS included that the atoll provided the only logistical support base with infrastructure on the eastern half of 
the NWHI, it was restricted from any commercial/ recreational activities, and there was an extensive apparent abundance of potential monk seal prey items available. Moreover, FFS has the largest monk seal subpopulation but the worst cohort survival rate among the youngest age classes, making it an important location to study foraging habitat, food availability, and other potential ecological implications which may be affecting their survival rates (R. Dollar, pers. obs.). Early collections were focused on shallow reef species based upon evidence from analysis of scat and spews (Goodman-Lowe 1998, Goodman-Lowe et al. 1999), and later collections were focused on obtaining slope and subphotic species based on feeding behavior observed in animal-borne imaging studies ('Crittercam;' Parrish et al. 2000, 2002). The broad range of habitats that the monk seal feeds across (reefs to subphotic depths) made for a very diverse collection of fish and invertebrate species sampled between depths of 10 and $500 \mathrm{~m}$. Upon capture, all fish and invertebrate specimens were frozen in airtight plastic bags with detailed records of location and habitat prior to being shipped to Dalhousie for analysis. Specimens were stored at $-20^{\circ} \mathrm{C}$ and processed within 6 mo. In total, 2190 specimens representing 100 species were analyzed for this study. An average sample size of 21 ind. species $^{-1}$ was used to generate the fatty acid signature of each species, with the exception of the spiny and slipper lobsters, for which 71 and 72 specimens were used, respectively.

FA analysis. Individual fishes and invertebrates were thawed and measured; fork length or carapace width was measured to the nearest $0.1 \mathrm{~cm}$, and body mass was measured to the nearest $0.1 \mathrm{~g}$. Each whole individual was then homogenized in a food processor. Stomach contents of individuals were not removed prior to homogenization given that we treated the individuals as prey eaten whole by consumers. Lipids were quantitatively extracted from each individual specimen in duplicate aliquots using a modified Folch method (Folch et al. 1957, Iverson et al. 2001); fat content is expressed as the average of the 2 duplicates. FAs were converted to FA methyl esters by acidic transesterification and analyzed using temperature-programmed gas liquid chromatography as described in Budge et al. (2002) and Iverson et al. (2002), on a Perkin Elmer Autosystem II Capillary FID gas chromatograph fitted with a $30 \mathrm{~m} \times 0.25 \mathrm{~mm}$ i.d. column coated with $50 \%$ cyanopropyl polysiloxane $(0.25 \mu \mathrm{m}$ film thickness; J\&W DB-23) and linked to a computerized integration system (Turbochrome 4.1 software, PE Nelson). Identification of FAs and isomers was determined from the following sources: known standard mixtures (Nu Check Prep.), silver-nitrate (argentation) chromatography, and gas chromatography-mass spectrometry. All sample chromatograms and FA identifications were individually examined for accuracy in identification and integration of peak areas, and corrected and reintegrated if necessary. FAs are named in the format $\mathrm{A}: \mathrm{Bn}-\mathrm{X}$, where $\mathrm{A}$ is the number of carbon atoms, B is the number of double bonds in the carbon chain, and $\mathrm{n}-\mathrm{X}$ represents the position of the first double bond relative to the methyl terminal end. FAs are expressed as mean mass percent of total FAs \pm SEM.

Ecological assessments and species grouping procedures. Due to the large number of species analyzed, the fact that some species were of key commercial or ecological importance, and the constraints of sample collection that led to small sample sizes for some species (e.g. $\mathrm{n}=4$ for Octopus ornatus), we explored meaningful ways to create groups of species. Although grouping species on the basis of taxonomical proximity alone might seem intuitive, closely related species (e.g. belonging to the same family, genus) can have very different diets and ecology, which will greatly influence their FA composition. For example, if we were to simply group all snapper species by that taxa (i.e. as 'snappers'), we would be grouping both shallow reef feeders with deep subphotic feeders, creating a different FA signature than found in any individual species. Therefore, a thorough analysis of the ecology of each species was performed, and a synthesis of the following factors was used to assign species to groups: taxonomy, diet, ecological subsystem (reef, bank, slope, or subphotic), habitat (live reef, isolated rock, sand, or carbonate substrate) and commercial interest. The diet of each species was estimated through a comparative study of published data (Hobson 1974, Parrish et al. 1986, Parrish 1989, Moffitt \& Parrish 1992, Seki \& Somerton 1994, Randall 1996, Hoover 1998, Humphreys 2000, Parrish \& Boland 2004, Parry 2006, Froese \& Pauly 2009, Palomares \& Pauly 2010). Crustaceans were classified as benthic carnivores that feed on the mix of bottom productivity and detritus. For fish, diet categories were assigned to each species following the model of trophic community composition suggested by Parrish (1989): benthic herbivore (browser, grazer), planktivore (algal planktivore, zooplanktivore), benthic carnivore (corallivore, invertebrate feeder), piscivore, and detritivore/omnivore. Cephalopods were divided into an octopus group that fed on benthic crustaceans and squid that fed on fish.

After an in-depth analysis of all data gathered, 47 groups composed of closely related and ecologically similar species were created. The number of species incorporated within a group ranged from 1 to 8 . Some key species of particular economic (fisheries) or ecological importance were treated individually and thus were not grouped with others (Polovina \& Mitchum 1992, Coffman \& Kim 2009, Kittinger et al. 2010). Spe- 
cies of commercial interest included the 3 species of snappers (Etelis carbunculus, Pristipomoides filamentosus, P. zonatus) and spiny lobsters Panulirus marginatus, which were all analyzed separately. In some instances, species which were the only representatives of their family and/or possessed distinctive ecology were not grouped with others.

Statistical analyses. FA data were analyzed using hierarchical cluster analysis, multivariate analysis of variance (MANOVA), and discriminant function analysis (DFA) using the stepwise method to assess which FAs accounted for most of the variance in group separation on the first 2 discriminant functions. We used the 15 dietary FAs (n-1 of the smallest species group sample size) that were either the most abundant and/or exhibited the greatest variance across all species, accounting for $\sim 86$ mass $\%$ of total FAs identified. These FAs included 14:0, 16:0, 16:1n-7, 18:0, 18:1n-9, 18:1n-7, 18:2n-6, 20:1n-9, 20:4n-6, 20:5n-3, 22:1n-11, 22:4n-6, 22:5n-6, 22:5n-3, and 22:6n-3. Hierarchical cluster analysis was used to evaluate the degree of similarity in FA signatures by sequentially merging the 47 groups into clusters, from the most to the least similar, with each cluster being nested within the next. The distance among clusters was computed by an agglomerative method using average linkage between groups and Euclidean distance measure. While this method did not require a reduction in the number of FAs to be used (total 74 FAs), the cluster analysis was conducted using the same 15 dietary FAs that were used in all MANOVAs and DFAs to render all results directly comparable. Percentage values for FAs were transformed into log ratios prior to DFA (see Budge et al. 2002, Iverson et al. 2002): the values for the 15 FAs were first re-normalized over $100 \%$, then each renormalized value was divided by the value for 18:0 (a reference FA). Given that the log of 0 cannot be taken, a value of $0.005 \%$ was added to any 0 values, the 15 ratios were log transformed, and the resulting log ratios were used in DFA. All data analyses were performed using SPSS V. 11.5 and R V. 2.6.2. Wilk's Lambda was used to assess the power of the discrimination among species/groups; the smaller the value, the more significant the difference. The percent of group cases correctly classified into their assigned groups was used to evaluate the performance of the classification function, and the classifications were cross-validated using a leave-one-out cross validation procedure. The predicted group membership of each species/group of species was examined for any consistent misclassification. Our statistical approach could thus be summarized as follows: hierarchical cluster analysis on 47 groups using 15 FAs $\rightarrow$ DFA among 47 groups using 15 FAs $\rightarrow$ individual DFA within 4 major functional groups using 15 FAs.

\section{RESULTS}

The fat content and FA composition (FAs used in analyses) of the 100 species analyzed ( $n=2190$ individuals) are presented in Table S2 in the supplement at www.int-res.com/articles/suppl/m418p001_supp.pdf. The ecological habitat and diet guild of each of these species was summarized (Table S3 in the supplement) and based upon these evaluations, species were grouped into 47 groups, composed of closely related and ecologically similar species (Table 1 ; Table S2 in the supplement), for subsequent analyses.

\section{Hierarchical cluster analysis}

For the 47 groups, the 15 FAs generally separated species according to the variables of diet and ecological subsystems (i.e. depth; Fig. 1). The first node isolated one of the subphotic fish, the armorhead, from all other groups. The second node grouped together 4 of the 5 groups of herbivores. The third node separated the cephalopods from all remaining groups. The fourth node separated the deep-water groups (subphotic and slope) from the other groups. The fifth node clustered together the crustaceans, except the shrimps, which were affiliated with the deep-water species. The sixth node grouped the carnivores, piscivores, planktivores, and omnivores together.

\section{Discriminant analysis among species groups}

DFA performed on the 47 species groups revealed separation primarily among herbivores, planktivores, carnivores, crustaceans, and cephalopods (Fig. 2). Fourteen significant discriminant functions were generated (Wilk's Lambda 0.518, p < 0.001), and groups were separated with $75.8 \%$ of cross-validated group cases; 1659 of 2190 individuals were correctly classified to their group. The FA which accounted for most of the variance in the separation of the 47 groups was 18:1n-9 (higher in deep-water species), followed by 16:0 (higher in herbivores and planktivores). A plot of the group centroids on the first 2 discriminant functions revealed that individuals with similar FA composition associated into 3 distinct clusters; all benthic herbivores $(n=310)$ were situated in the upper left quadrant, crustaceans ( $\mathrm{n}=352$ ) were mainly distributed in the upper right quadrant, and all carnivorous fishes, which included benthic carnivores, omnivores/ detritivores, and piscivores $(\mathrm{n}=1281)$, were predominantly scattered in the lower left and right quadrants (Fig. 2). The 2 groups of cephalopods $(\mathrm{n}=55)$ were both positioned in the upper right quadrant but were 
Table 1. Summary of groupings of 100 species of Northwestern Hawaiian Islands fish and invertebrates into 47 groups based on taxonomy, diet, and ecological evaluation from the literature (see Table S2 in the supplement at www. int-res.com/articles/suppl/m418p001_supp.pdf). Diet guilds$\mathrm{BH}$ : benthic herbivore, Pl: planktivore, Ps: piscivore, BC: benthic carnivore, Om: omnivore

\begin{tabular}{|c|c|c|c|}
\hline Group & $\begin{array}{c}\text { No. of } \\
\text { species }\end{array}$ & $\begin{array}{l}\text { No. of } \\
\text { ind. }\end{array}$ & $\begin{array}{l}\text { Diet } \\
\text { guild }\end{array}$ \\
\hline 1. Angelfish & 1 & 20 & $\mathrm{BH}$ \\
\hline 2. Cardinalfish & 1 & 18 & $\mathrm{Pl}$ \\
\hline 3. Armorhead & 1 & 20 & $\mathrm{Pl}$ \\
\hline 4. Beardfish & 1 & 20 & $\mathrm{BC}$ \\
\hline 5. Bigeye & 2 & 40 & Ps \\
\hline 6. Cusk eel & 1 & 20 & Ps \\
\hline 7. Conger eel & 2 & 46 & Ps \\
\hline 8. Butterfly/forcepfish & 6 & 134 & $\mathrm{BC}$ \\
\hline 9. Pennantfish & 1 & 36 & $\mathrm{Pl}$ \\
\hline 10. Cutthroat/snake eel & 2 & 39 & Ps \\
\hline 11. Sergeant & 3 & 57 & $\mathrm{Pl}$ \\
\hline 12. Chromis/dascyllus & 2 & 41 & $\mathrm{Pl}$ \\
\hline 13. Dragonet & 1 & 20 & $\mathrm{BC}$ \\
\hline 14. Gurnard & 1 & 24 & $\mathrm{BC}$ \\
\hline 15. Goatfish (Mulloidichthys spp.) & 2 & 41 & $\mathrm{BC}$ \\
\hline 16. Goatfish (Parupeneus spp.) & 4 & 77 & $\mathrm{BC}$ \\
\hline 17. Flounder & 3 & 116 & $\mathrm{BC}$ \\
\hline 18. Lizard/snakefish & 3 & 59 & Ps \\
\hline 19. Sandperch & 1 & 18 & $\mathrm{BC}$ \\
\hline 20. Moray eel & 7 & 135 & Ps \\
\hline 21. Parrotfish & 3 & 60 & $\mathrm{BH}$ \\
\hline 22. Toby & 4 & 80 & $\mathrm{BC}$ \\
\hline 23. Chub & 2 & 38 & $\mathrm{BH}$ \\
\hline 24. Scorpionfish & 1 & 19 & $\mathrm{BC}$ \\
\hline 25. Squirrelfish snapper & 1 & 21 & $\mathrm{BC}$ \\
\hline 26. Bluestripe snapper & 1 & 22 & Om \\
\hline 27. Pink snapper & 1 & 24 & $\mathrm{BC}$ \\
\hline 28. Flower snapper & 1 & 19 & $\mathrm{Om}$ \\
\hline 29. Soldierfish & 1 & 20 & $\mathrm{BC}$ \\
\hline 30. Squirrelfish & 1 & 21 & $\mathrm{BC}$ \\
\hline 31. Tang/surgeonfish & 8 & 154 & $\mathrm{BH}$ \\
\hline 32. Unicornfish & 2 & 38 & $\mathrm{BH}$ \\
\hline 33. Tilefish & 1 & 16 & $\mathrm{BC}$ \\
\hline 34. Knife/razorfish & 3 & 57 & $\mathrm{BC}$ \\
\hline 35. Triggerfish (Melichthys spp.) & 1 & 20 & $\mathrm{Pl}$ \\
\hline 36. Triggerfish (Sufflamen spp.) & 1 & 19 & $\mathrm{BC}$ \\
\hline 37. Wrasse/hogfish/coris & 7 & 135 & $\mathrm{BC}$ \\
\hline 38. Octopus & 3 & 40 & $\mathrm{BC}$ \\
\hline 39. Squid & 1 & 15 & Ps \\
\hline 40. Shrimp & 2 & 70 & $\mathrm{BC}$ \\
\hline 41. Box crab & 2 & 59 & $\mathrm{BC}$ \\
\hline 42. Swimming crab & 1 & 29 & $\mathrm{BC}$ \\
\hline 43. Pebble crab & 1 & 21 & $\mathrm{BC}$ \\
\hline 44. Slipper lobster & 2 & 102 & $\mathrm{BC}$ \\
\hline 45. Spiny lobster & 1 & 71 & $\mathrm{BC}$ \\
\hline 46. Boarfish & 2 & 20 & $\mathrm{BC}$ \\
\hline 47. Duckbill & 1 & 19 & $\mathrm{BC}$ \\
\hline Total & 100 & 2190 & \\
\hline
\end{tabular}

spatially distinct from one another. Most planktivores $(\mathrm{n}=172)$ were located at the interface of the herbivore and carnivore cluster, with the exception of the planktivorous armorhead Pseudopentaceros wheeleri $(\mathrm{n}=$ 20); armorheads were tightly clustered in the lower right quadrant, and this group was spatially isolated from all others on the first 2 discriminant functions.
Fig. 2 also revealed separation among groups as a function of habitat/ecological subsystem. The majority of the deep-water species were located in the lower right quadrant: armorhead (Group 3; P. wheeleri), beardfish $(4 ;$ Polymixia berndti), cutthroat/snake eel (10; Meadia abyssalis and Ophichthus kunaloa), squirrelfish snapper (25; Etelis carbunculus), flower snapper (28; Pristipomoides zonatus), shrimp (40; Heterocarpus ensifer and H. laevigatus), and duckbill (47; Bembrops filifera), suggesting that species living at depth have distinct and somewhat characteristic FA signatures.

The proportion of individuals correctly classified was high in the majority of the 47 groups analyzed (Table 2); the groups angelfish (1), armorhead (3), scorpionfish (24) and shrimp (40) had $100 \%$ of crossvalidated grouped cases correctly classified, and more than half of the groups (27/47) exhibited a classification success $>80 \%$ (Groups $1,2,3,6,9,10,13,14,17$, $18,19,20,21,23,24,25,28,31,32,35,36,38,39,40$, $42,46,47)$. However, 5 groups were classified poorly, with $<60 \%$ individuals correctly classified: the groups chromis/dascyllus (12), the box crab (41), the conger eel (7), the knife/razorfish (34), and the Parupeneus goatfish (16) (see Table 2 for details). However, most misclassifications occurred among groups with similar diet and/or ecology. Classification success was high in the 2 cephalopod groups. The few misclassified octopuses were classified as squids and vice versa. Interestingly, cephalopods did not cluster together in this DFA analysis, which suggests substantial differences in their FA content despite their taxonomical relatedness.

\section{Fat content and fatty acid composition among functional groups}

The average FA composition (mean \pm SD) for each individual functional group (i.e. herbivores, planktivores, carnivores, crustaceans, and cephalopods) and for each of the 47 species groups is presented in Table $\mathrm{S} 4$ in the supplement at www.int-res.com/ articles/suppl/m418p001_supp.pdf. Average fat content varied significantly across functional groups (ANOVA, $F=838.65$, Tukey HSD post hoc test, $\mathrm{p}<0.001$ ). Fat contents among herbivores and planktivores were comparable at 3.7 and $3 \%$ fat, respectively. Crustaceans had the lowest percentage of fat $(1.2 \%)$, while cephalopods and carnivores were similar at 1.4 and $2 \%$ fat, respectively. The armorhead exhibited a drastically higher fat content at $27 \%$ fat.

The 15 FAs used in the analyses were significantly different across the 6 functional groups at the 0.05 significance level (Wilk's Lambda 0.032, Tukey HSD post hoc test, $\mathrm{p}<0.001$ ). We will focus on the 5 most abun- 


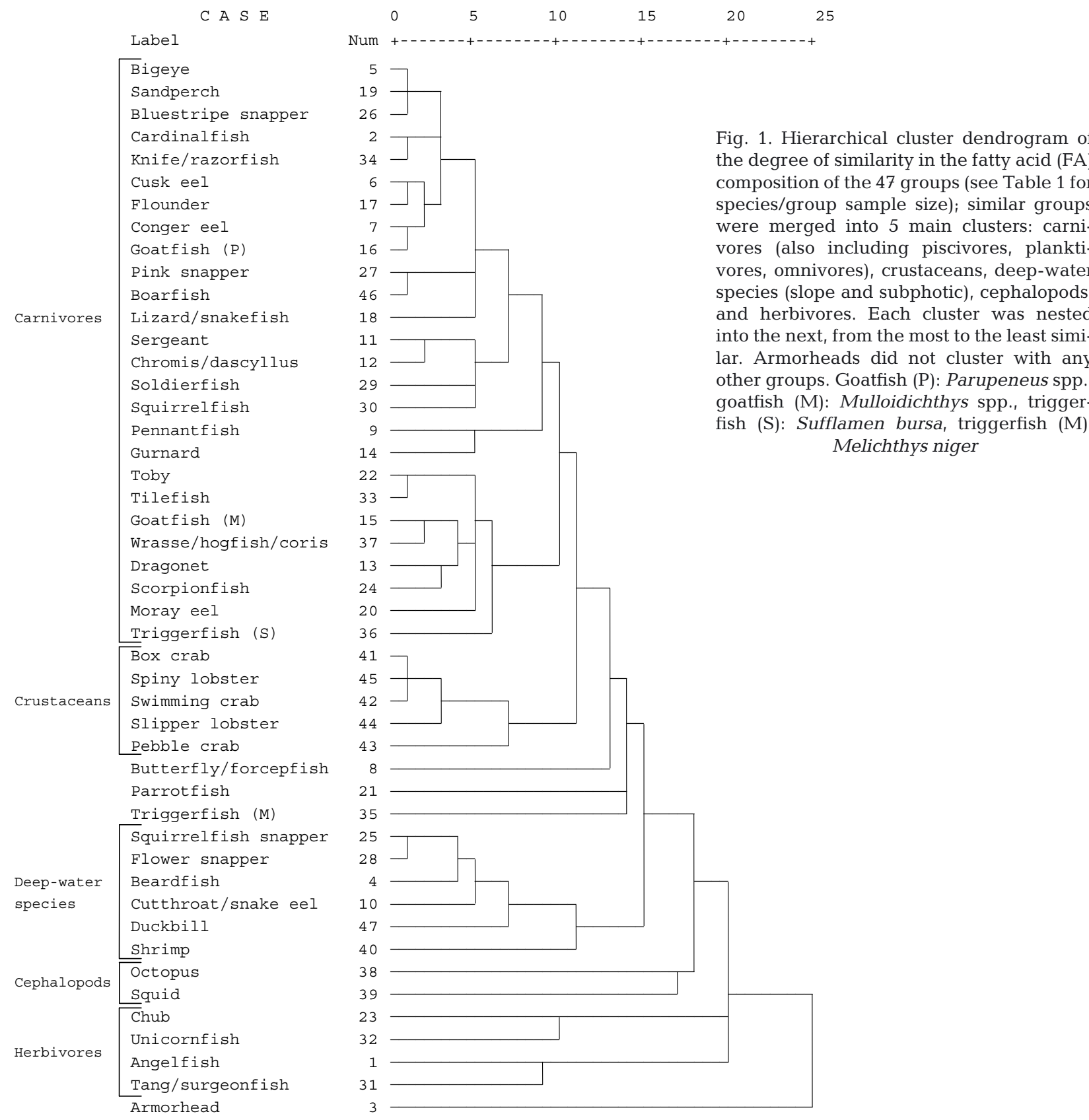

dant FAs, which accounted for $\sim 60 \%$ of total FA in NWHI species: 16:0, 18:1n-9, 20:4n-6, 20:5n-3, and $22: 6 \mathrm{n}-3$. On average, herbivores had the highest proportion of $16: 0$ at $30 \%$, while $16: 0$ contents in other functional groups ranged from $26 \%$ in planktivores to $14 \%$ in crustaceans (Table S4). Armorhead contained a markedly higher content of $18: 1 \mathrm{n}-9$ at $26.5 \%$, while cephalopods contained the lowest $(4 \%)$. Levels of $20: 4 n-6$ were noticeably lower in armorheads at $0.6 \%$, and were the highest on average in crustaceans $(11 \%)$. Cephalopods and crustaceans contained the highest proportion of $20: 5 n-3$ at 10 and $9 \%$ respectively, in comparison with herbivores $(7 \%)$, carnivores and planktivores $(5 \%)$ and armorhead $(4.5 \%)$. Cephalopods also exhibited the highest proportion of $22: 6 n-3$ at $26.5 \%$, followed by carnivores $(18 \%)$, planktivores $(14 \%)$, armorheads $(13 \%)$, crustaceans $(11 \%)$, and herbivores $(5 \%)$.

\section{Discriminant analyses within functional groups}

To increase the resolution of our investigation and evaluate variation in FA composition between groups 
Fig. 2. Group centroids (withingroup mean for each discriminant function) for the first and second (of 14 significant) discriminant functions, which accounted for $49 \%$ of total variance, for discriminant function analysis performed on the 47 species groups $(n=2190$; see Table 1 for species/group names and sample sizes) using the 15 fatty acids (FAs) that exhibited the greatest average variance, abundance, and reflection of diet. The 2 FAs which accounted for most of the variance in group separation on the first 2 discriminant functions were 18:1n-9 and 16:0

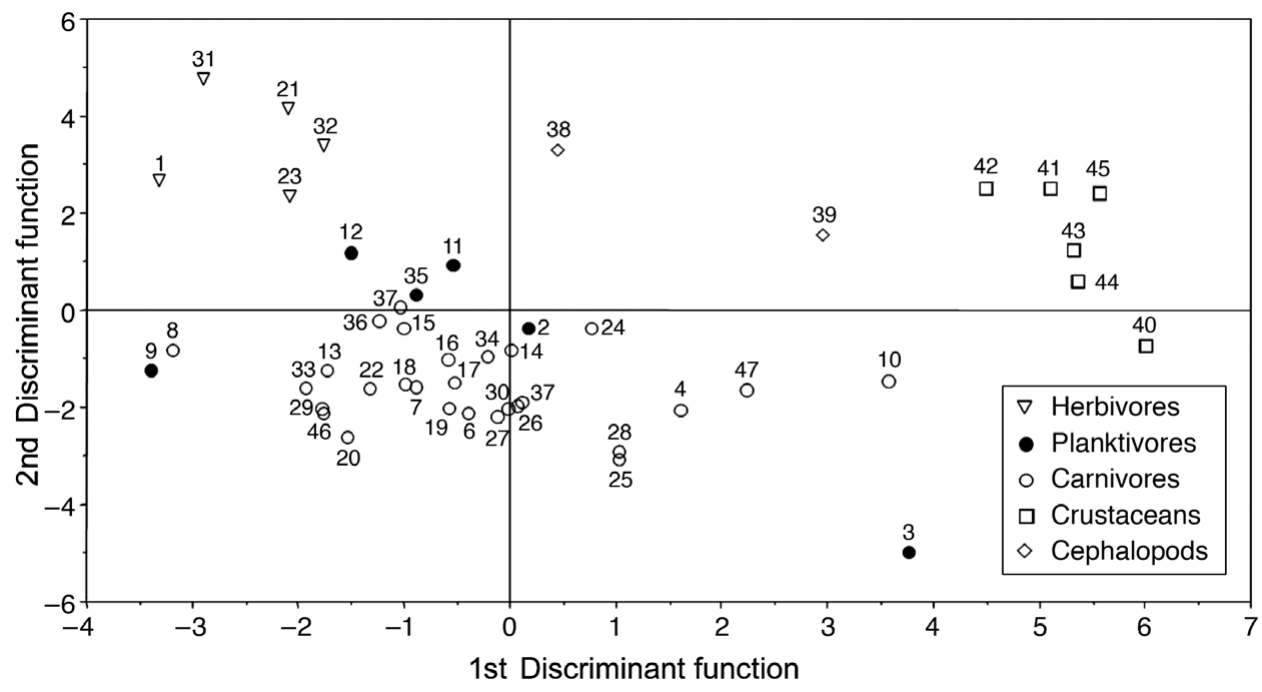

in more detail, subsequent DFAs were conducted using the selected 15 FAs on each of the 4 major functional groups separately (herbivores, planktivores, carnivores, and crustaceans). The FA signatures of the 2 cephalopod groups were also analyzed and contrasted.

\section{Herbivores}

DFA performed on the 5 groups of herbivores $(\mathrm{n}=$ 310; angelfish, Group 1; parrotfish 21; chub 23; tang/surgeonfish 31; unicornfish 32) yielded a crossvalidated classification success of $97.7 \%$. Four significant discriminant functions were generated (Wilk's Lambda $0.345, \mathrm{p}<0.001$ ). All groups contained an extremely high proportion of correctly classified individuals, with classification success ranging from 95 to $100 \%$ (Table 2). A plot of the discriminant scores and group centroids on the first 2 discriminant functions (Fig. 3), revealed that parrotfish (21) had a more distinct FA signature as they clustered by themselves in the lower left quadrant. The unicornfish (27) and chub (18) groups, as well as the angelfish and tang/ surgeonfish groups formed 2 separate clusters and appeared to be partly overlaid on the plot (Fig. 3). Nevertheless, the 4 aforementioned groups all had a high number of individuals correctly classified (see Table 2), indicating that they would likely be separated on the remaining discriminant functions, and that they are distinguishable on the basis of their FA signatures.

Differences in FA levels were significant across the 5 groups of herbivores (Wilk's Lambda 0.002, p < 0.001). Tang/surgeonfish (26) had high levels of $16: 0$ at $32 \%$, and chubs (18) had the lowest (25\%). Unicornfish (27) exhibited the highest proportion of $18: 1 \mathrm{n}-9$ at $11.5 \%$, relative to the other groups of herbivores (6 to $10 \%$ ). Parrotfish (16) had higher levels of $20: 4 n-6$ at $12.5 \%$, while tang/surgeonfish (26) and unicornfish (27) had the lowest ( 7 and $6.5 \%$, respectively). Tang/surgeonfish exhibited the highest levels of 20:5n-3 at $8 \%$. Levels of $22: 6 n-3$ where the highest in chubs (18) at $9 \%$ relative to the other herbivores $(3-5 \%)$.

\section{Planktivores}

The planktivorous armorheads clearly separated from all other planktivores and clustered tightly by themselves in the DFA on the 47 groups (Fig. 2). Armorheads are thus readily distinguishable from the other groups of planktivores, as well as from all other species groups analyzed. As such, they are treated and discussed separately in the section 'Armorheads' below. DFA conducted on the remaining 5 groups of planktivores $(\mathrm{n}=172$; cardinalfish 2; pennantfish 9; sergeant 11; chromis/dascyllus 12; triggerfish M 35) yielded a cross-validated classification success of $87.2 \%$. Four significant functions were generated (Wilk's Lambda 0.204, p < 0.001). A plot of the scores and group centroids on the first and second discriminant functions revealed that Melichthys niger triggerfish (35) and Heniochus diphreutes pennantfish (9) were spatially isolated from the other planktivores (Fig. 3). M. niger had the lowest levels of 14:0 and this FA accounted for most of the variance in the separation along the first discriminant function. $H$. diphreutes had the lowest proportion of $18: 1 n-9$, the FA which accounted for most of the variance on the second function. Moreover, $M$. niger and $H$. diphreutes had the highest $(9.7 \%)$ and lowest (2\%) levels of 20:4n-6, respectively. Classification success was high (>80\%) for all groups of planktivores, with the exception of the chromis/dascyllus group (12) for which $19.5 \%$ of individuals were misclassified as sergeant (11; see Table 2$)$. 
Table 2. Predicted group membership for discriminant function analyses (DFAs) among the 47 groups of species, and within the 4 main functional groups: herbivores, planktivores, crustaceans, and carnivores (including piscivores and omnivores). The armorhead and cephalopod groups were excluded from the within functional group analyses. The number and proportion of individuals correctly classified, and the major misclassifications for (bold, see footnotes) groups with $<60 \%$ individuals correctly classified are reported

\begin{tabular}{|c|c|c|c|c|c|c|}
\hline \multirow{2}{*}{$\begin{array}{l}\text { Functional } \\
\text { group }\end{array}$} & \multirow[t]{2}{*}{ Group of species } & \multirow{2}{*}{$\begin{array}{l}\text { No. of } \\
\text { ind. }(\mathrm{n})\end{array}$} & \multicolumn{2}{|c|}{ DFA among 47 groups } & \multicolumn{2}{|c|}{ DFA within 4 functional groups } \\
\hline & & & Count & $\%$ & Count & $\%$ \\
\hline \multirow[t]{5}{*}{ Herbivores } & 1. Angelfish & 20 & 20 & 100.0 & 19 & 95.0 \\
\hline & 21. Parrotfish & 60 & 57 & 95.0 & 60 & 100.0 \\
\hline & 23. Chub & 38 & 32 & 84.2 & 38 & 100.0 \\
\hline & 31. Tang/surgeonfish & 154 & 138 & 89.6 & 150 & 97.4 \\
\hline & 32. Unicornfish & 38 & 36 & 94.7 & 36 & 94.7 \\
\hline \multirow[t]{6}{*}{ Planktivores } & 2. Cardinalfish & 18 & 15 & 83.3 & 17 & 94.4 \\
\hline & 3. Armorhead & 20 & 20 & 100.0 & N/A & N/A \\
\hline & 9. Pennantfish & 36 & 32 & 88.9 & 35 & 97.2 \\
\hline & 11. Sergeant & 57 & 32 & 56.1 & 48 & 84.2 \\
\hline & 12. Chromis/dascyllus & 41 & 18 & $43.9^{a}$ & 30 & 73.2 \\
\hline & 35. Triggerfish (Melichthys niger) & 20 & 18 & 90.0 & 20 & 100.0 \\
\hline \multirow[t]{28}{*}{ Carnivores } & 4. Beardfish & 20 & 15 & 75.0 & 16 & 80.0 \\
\hline & 5. Bigeye & 40 & 29 & 72.5 & 30 & 75.0 \\
\hline & 6. Cusk eel & 20 & 17 & 85.0 & 16 & 80.0 \\
\hline & 7. Conger eel & 46 & 17 & $37.0^{b}$ & 15 & $32.6^{f}$ \\
\hline & 8. Butterfly/forcepfish & 134 & 91 & 67.9 & 109 & 81.3 \\
\hline & 10. Cutthroat/snake eel & 39 & 37 & 94.9 & 37 & 94.9 \\
\hline & 13. Dragonet & 20 & 17 & 85.0 & 18 & 90.0 \\
\hline & 14. Gurnard & 24 & 20 & 83.3 & 20 & 83.3 \\
\hline & 15. Goatfish (Mulloidichthys spp.) & 41 & 28 & 68.3 & 28 & 68.3 \\
\hline & 16. Goatfish (Parupeneus spp.) & 77 & 32 & $41.6^{\mathrm{c}}$ & 34 & $44.2^{\mathrm{g}}$ \\
\hline & 17. Flounder & 116 & 94 & 81.0 & 98 & 84.5 \\
\hline & 18. Lizard/snakefish & 59 & 49 & 83.1 & 45 & 76.3 \\
\hline & 19. Sandperch & 18 & 15 & 83.3 & 15 & 83.3 \\
\hline & 20. Moray eel & 135 & 111 & 82.2 & 110 & 81.5 \\
\hline & 22. Toby & 80 & 63 & 78.8 & 58 & 72.5 \\
\hline & 24. Scorpionfish & 19 & 19 & 100.0 & 19 & 100.0 \\
\hline & 25. Squirrelfish snapper & 21 & 19 & 90.5 & 19 & 90.5 \\
\hline & 26. Bluestripe snapper & 22 & 14 & 63.6 & 14 & 63.6 \\
\hline & 27. Pink snapper & 24 & 16 & 66.7 & 17 & 70.8 \\
\hline & 28. Flower snapper & 19 & 18 & 94.7 & 18 & 94.7 \\
\hline & 29. Soldierfish & 20 & 15 & 75.0 & 17 & 85.0 \\
\hline & 30. Squirrelfish & 21 & 14 & 66.7 & 14 & 66.7 \\
\hline & 33. Tilefish & 16 & 12 & 75.0 & 14 & 87.5 \\
\hline & 34. Knife/razorfish & 57 & 30 & $52.6^{d}$ & 33 & $57.9^{\mathrm{h}}$ \\
\hline & 36. Triggerfish (Sufflamen bursa) & 19 & 18 & 94.7 & 17 & 89.5 \\
\hline & 37. Wrasse/hogfish/coris & 135 & 82 & 60.7 & 96 & 71.1 \\
\hline & 46. Boarfish & 20 & 19 & 95.0 & 19 & 95.0 \\
\hline & 47. Duckbill & 19 & 17 & 89.5 & 17 & 89.5 \\
\hline \multirow[t]{6}{*}{ Crustaceans } & 40. Shrimp & 70 & 70 & 100.0 & 70 & 100.0 \\
\hline & 41. Box crab & 59 & 24 & $40.7^{\mathrm{e}}$ & 33 & $55.9^{\mathrm{i}}$ \\
\hline & 42. Swimming crab & 29 & 24 & 82.8 & 27 & 93.1 \\
\hline & 43. Pebble crab & 21 & 15 & 71.4 & 16 & 76.2 \\
\hline & 44. Slipper lobster & 102 & 79 & 77.5 & 89 & 87.3 \\
\hline & 45. Spiny lobster & 71 & 49 & 69.0 & 51 & 71.8 \\
\hline \multirow[t]{2}{*}{ Cephalopods } & 38. Octopus & 40 & 38 & 95.0 & N/A & N/A \\
\hline & 39. Squid & 15 & 14 & 93.3 & N/A & N/A \\
\hline \multicolumn{2}{|l|}{ Total: } & 2190 & & & & \\
\hline \multicolumn{3}{|c|}{$\begin{array}{l}\text { Major misclassifications (\%, group number) for DFA on } 47 \\
\text { groups: }\end{array}$} & \multicolumn{4}{|c|}{$\begin{array}{l}\text { Major misclassifications (\%, group number) for DFAs } \\
\text { within functional groups: }\end{array}$} \\
\hline \multicolumn{3}{|c|}{$\mathrm{a} 17.1 \%, 31 ; 14.6 \%, 11 ; 7.3 \%, 14$} & \multicolumn{4}{|c|}{${ }^{\mathrm{f}} 21.7 \%, 20 ; 15.2 \%, 34 ; 15.2 \%, 18$} \\
\hline \multicolumn{3}{|c|}{${ }^{\mathrm{b}} 21.7 \%, 20 ; 17.4 \%, 18 ; 13.0 \%, 34$} & \multicolumn{4}{|c|}{${ }^{9} 19.5 \%, 19 ; 10.4 \%, 24 ; 5.2 \%, 15 ; 6.5 \%, 6$} \\
\hline \multicolumn{3}{|c|}{${ }^{\mathrm{c}} 18.2 \%, 19 ; 9.1 \%, 24 ; 7.8 \%, 15 ; 5.2 \%, 6 ; 5.2 \%, 2$} & $\mathrm{~h}_{15.8} \%$ & ; $8.8 \%, 24$ & $3 \%, 18 ; 5.3 \%, 6$ & \\
\hline $\mathrm{d}_{14.0 \%, 16 ; 14}$ & $0 \%, 2 ; 5.3 \%, 18 ; 5.3 \%, 6$ & & ${ }^{\mathrm{i}} 23.7 \%$ & $8.5 \%, 44$ & $\%, 43 ; 5.1 \%, 4$ & \\
\hline${ }^{\mathrm{e}} 30.5 \%, 45 ; 10$ & $2 \%, 43 ; 6.8 \%, 42 ; 5.1 \%, 44$ & & & & & \\
\hline
\end{tabular}




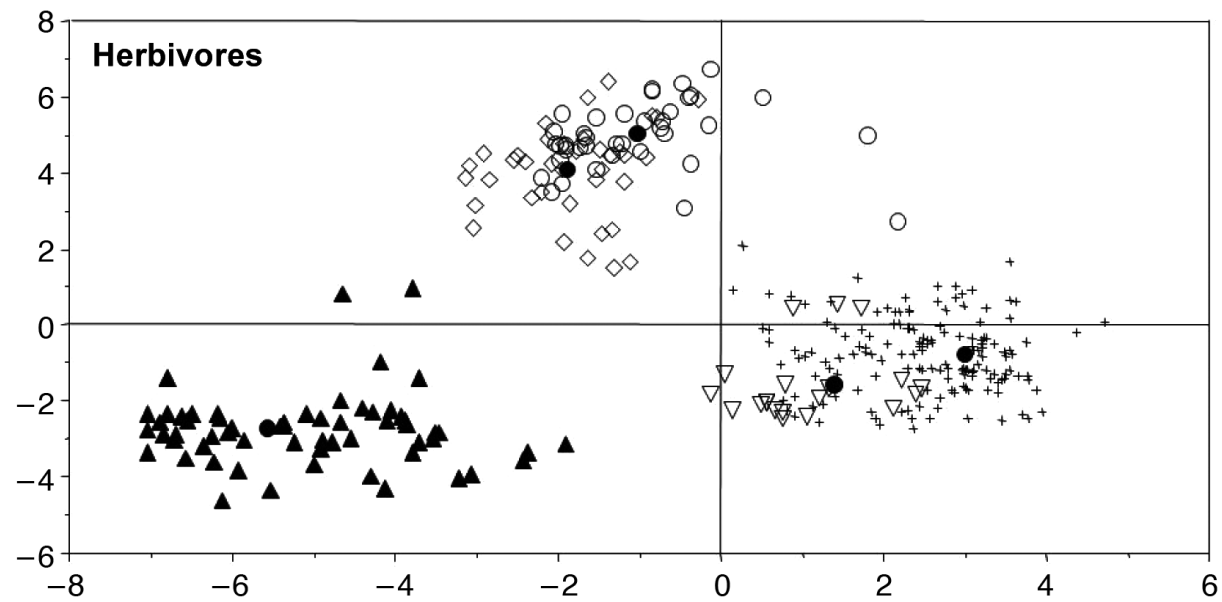

$\nabla$ Angelfish

A Parrotfish

$\diamond$ Chub

+ Tang/surgeonfish

O Unicornfish

Group centroids

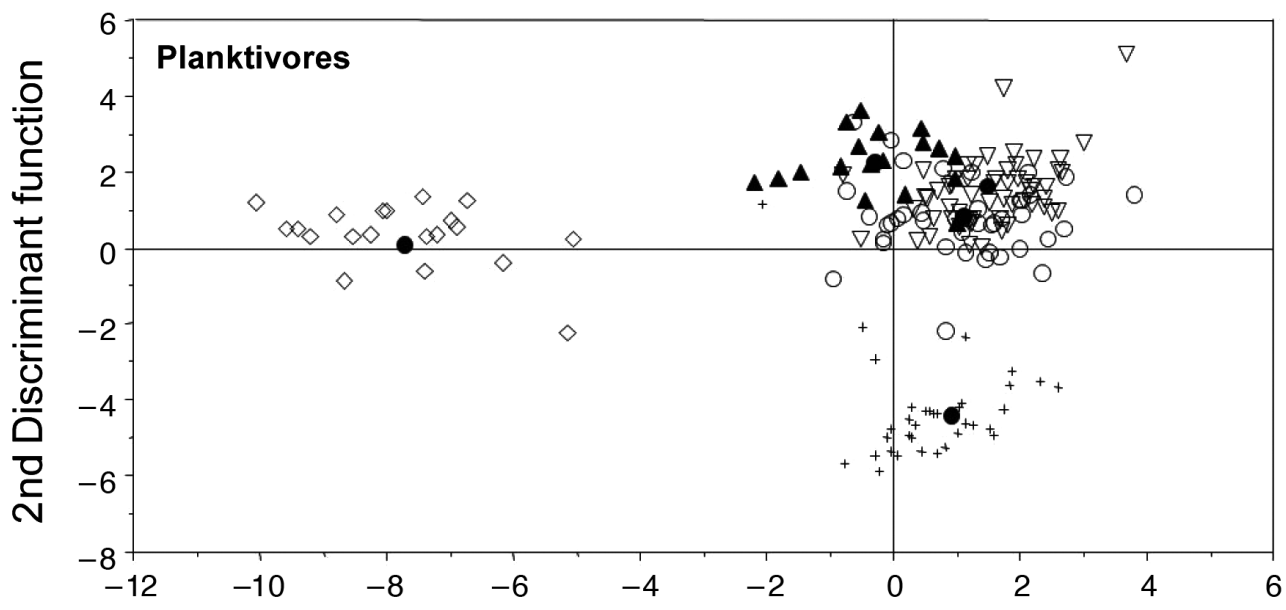

- Cardinalfish

+ Pennantfish

$\nabla$ Sergeant

Chromis/dascyllus

$\diamond$ Triggerfish $\mathrm{M}$

- Group centroids

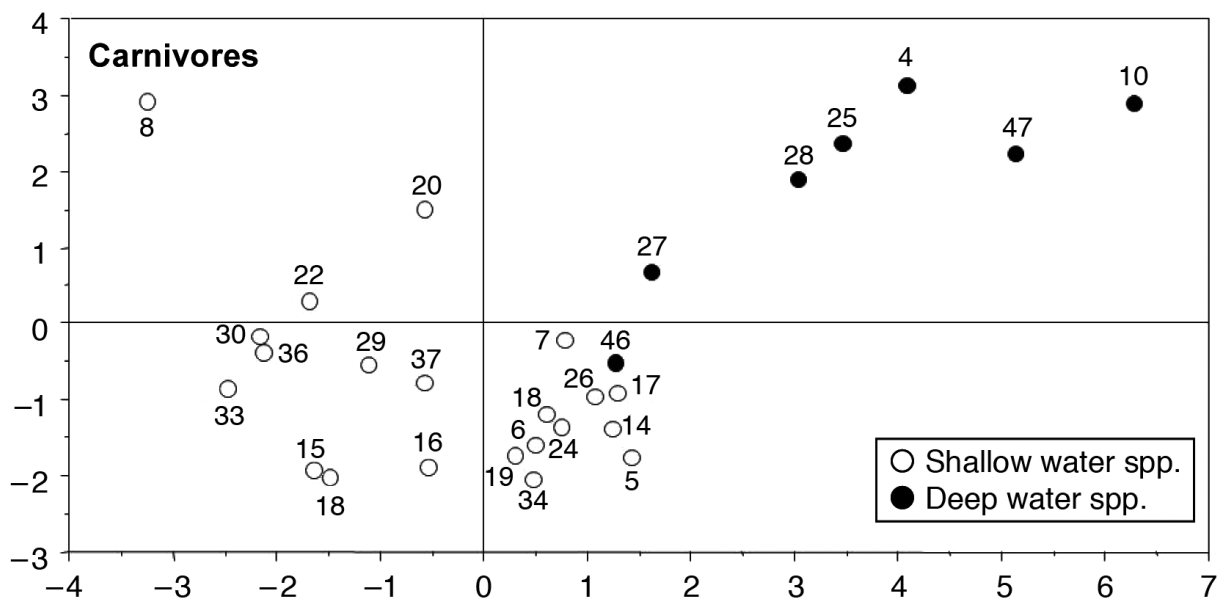

1st Discriminant function

Fig. 3 (this and the next page). Discriminant scores and group centroids (within-group mean for each discriminant function) for the discriminant function analyses (DFAs) conducted on the 4 functional groups: herbivores $(n=310)$, planktivores $(n=172)$, carnivores $(\mathrm{n}=1281)$, and crustaceans $(\mathrm{n}=352)$. The armorhead group (Pseudopentaceros wheeleri, $\mathrm{n}=20)$ was excluded from the DFA performed on planktivores. For clarity purposes, only the group centroids are presented for the carnivore DFA (see Table 2 for species/group names). The first 2 discriminant functions accounted for $85,90,54.3$, and $84.4 \%$ of the total variance in herbivores, planktivores, carnivores, and crustaceans, respectively. The 2 fatty acids (FAs) which accounted for most of the variance on the first 2 discriminant functions were 20:1n-9 and 16:0 in herbivores, 14:0 and 18:1n-9 in planktivores, 18:1n-9 and 22:4n-6 in carnivores, and 


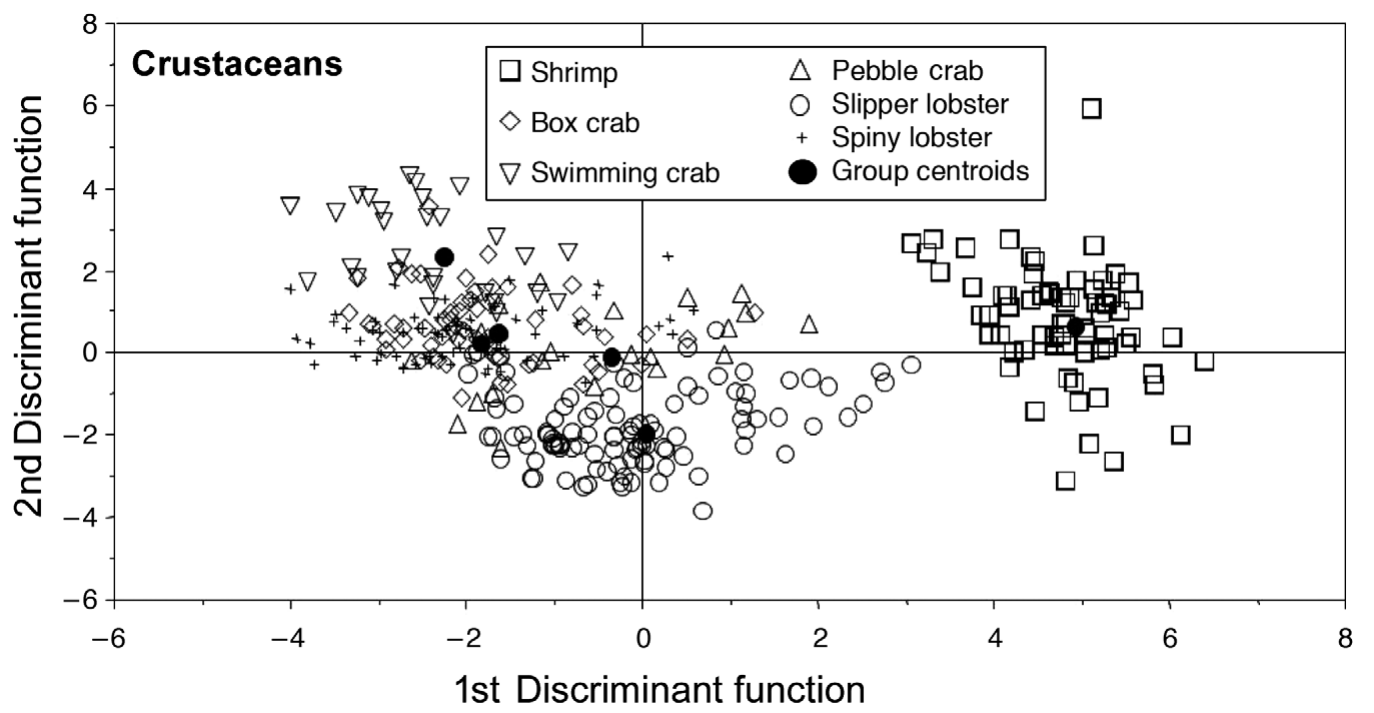

Fig. 3 (continued)

Conversely, the classification success of chromis/dascyllus was much lower in the DFA conducted on all 47 groups $(43.9 \%)$, which indicates that these fishes can be distinguished from other planktivores.

\section{Carnivores}

DFA performed on the 28 groups encompassed in the carnivore cluster $(\mathrm{n}=1281$; beardfish 4 , bigeye 5, cusk eel 6, conger eel 7, butterfly/forcepfish 8, cutthroat/ snake eel 10, dragonet 13, gurnard 14, goatfish M 15, goatfish P 16, flounder 17, lizard/snakefish 18, sandperch 19 , moray 20 , toby 22 , scorpionfish 24 , squirrelfish snapper 25, bluestripe snapper 26, pink snapper 27, flower snapper 28, soldierfish 29, squirrelfish 30 , tilefish 33, knife/razorfish 34, triggerfish S 36, wrasse/ hogfish/coris 37, boarfish 46, and duckbill 47) yielded a cross-validated classification success of $75.5 \%$. Fourteen significant discriminant functions were generated (Wilk's Lambda 0.790, p < 0.001). For more than half of the carnivores (17/28), classification success was $\geq 80 \%$ (Table 2). Three groups were poorly classified $(<60 \%$ individuals correctly classified), and most misclassifications occurred among groups with similar diet/ecology. A plot of the group centroids on the first 2 discriminant functions (Fig. 3) showed that groups thriving at subphotic depths $(4,10,47)$ and all deep-water groups living on the slope $(25,27,28)$ assembled together in the upper right quadrant. Nine groups inhabiting bank summits $(5,6,7,14,17,18,19,24,34)$ were located in the lower right quadrant, along with the bluestripe snapper (26), which occurs in shallow reef lagoons but also on outer reef slopes, and the duckbill (46) which are subphotic fishes with a flexible depth range
(Table S3 in the supplement). The remaining 11 groups, consisting of 7 reef $(8,15,16,20,29,36,37)$ and 4 bank $(13,22,30,33)$ groups, were scattered in the lower and upper left quadrant. Thus, carnivorous deep-water species (i.e. species thriving on the slopes and at subphotic depths), were differentiated from species living at shallower depths on the basis of their FA signatures. Correspondingly, carnivores living on bank summits and coral reefs associated more closely on the plot and thus had more similar FA composition.

MANOVA conducted on the 15 FAs used in the DFA showed that variations in FA composition among groups of carnivores were significant (Wilk's Lambda $0.001, \mathrm{p}<0.001)$. The 6 groups of deep-water species located in the upper right quadrant $(4,10,25,27,28,47)$ exhibited on average the highest levels of $18: 1 \mathrm{n}-9$ at $15 \%$, relative to $9 \%$ in groups thriving at moderate depths (banks) and in the shallows (reefs). The butterfly/forcepfish (8) were the only group spatially isolated from the other carnivores; they exhibited the highest levels of $22: 4 n-6(5 \%)$ relative to $\sim 2 \%$ in the other groups. The butterfly/forcepfish (8), moray eel (20), and toby (22) groups had the lowest levels of 20:5n-3 (2.8\% on average), while levels of $20: 5 n-3$ reached $7.6 \%$ in knife/razorfish (34). The average proportion of 20:4n-6 in deep-water groups ( $3 \%$ ) was less than half of the average proportion encountered in reef and bank groups (7\%). Levels of 22:6n-3 were higher in deep-water carnivores at $23 \%$ relative to the reef/bank groups (15\%).

\section{Crustaceans}

DFA performed on the 6 groups of crustaceans $(\mathrm{n}=$ 352; shrimp 40, box crab 41, swimming crab 42, pebble 
crab 43, slipper lobster 44, spiny lobster 45) yielded a cross-validated classification success of $81.5 \%$. Five significant discriminant functions were generated (Wilk's Lambda 0.447, p < 0.001). A plot of individual scores and group centroids on the first 2 discriminant functions (Fig. 3) showed that shrimps (40) were clearly separated from the 5 other crustacean groups. Classification success was high in the shrimps (40), swimming crabs (42), and slipper lobsters (44), which suggested that these 3 groups have more distinct FA signatures (Table 2). Some overlap was detected among the remaining crab $(41,43)$ and spiny lobster (45) groups. For example, the box crabs Calappa spp. (41) and spiny lobster Panulirus marginatus (45) were consistently misclassified as one another: $25.4 \%$ of box crabs were classified as spiny lobster, and $17 \%$ of spiny lobsters were incorrectly classified as box crabs. This indicates a fairly high degree of similarity among the FA composition of these 2 groups, which renders these crustaceans harder to distinguish on the basis of the 15 FAs used in this analysis.

Significant differences in FA composition (15 FAs) were detected among crustaceans (Wilk's Lambda 0.016, p < 0.001). On average, swimming crabs (42) and pebble crab (43) had the highest levels of 16:0 at $\sim 16 \%$. Shrimps (40) had high levels of 18:1n-9 (18\%), relative to $12 \%$ on average in the other groups. Spiny lobsters (45), box crabs (41), and swimming crabs (42) all had high levels of 20:4n-6 ( 15\%), while shrimps (40) comparatively had low levels (3.6\%). However, shrimps (40) exhibited a high proportion of 20:5n-3 at $11 \%$ relative to $9 \%$ in the other groups. Levels of $22: 6 n-3$ were also the highest in shrimps (40) at $14.5 \%$ relative to approximately $11 \%$ in the crab and lobster groups (41 to 45 ).

\section{Cephalopods}

Although DFA on the 47 groups of species showed that octopus (38) and squid (39) possessed distinct FA compositions with high classification success (Table 2), these cephalopods did not associate closely on the first 2 discriminant functions (Fig. 2), despite sharing similar, carnivorous diets (Table S3 in the supplement). Significant differences in FA levels among octopus (38) and squid (39) were detected (MANOVA, Wilk's Lambda 0.057, p < 0.001). Specifically, octopus had particularly high levels of 20:4n-6 (13.5\%) relative to squid ( $3 \%)$. Squid, on the other hand, had high levels of 18:1n-9 $(\sim 7 \%)$ and very high levels of $22: 6 n-3$ $(\sim 34 \%)$, while these FAs were present in lower proportion in octopus ( $\sim 3$ and $\sim 24 \%$, respectively). Of all species groups analyzed, squid had the highest levels of $22: 6 n-3$.
Armorheads

Planktivorous armorheads had $100 \%$ correctly classified individuals in the DFA of the 47 groups, and were spatially distinct from all groups. Armorheads had very high levels of $18: 1 \mathrm{n}-9$ at $26.54 \%$, which is atypical not only of planktivores, but also of any species group in this system. Armorheads also exhibited very low levels of 20:4n-6 at $\sim 0.6 \%$, which was also uncommon in NWHI species.

\section{DISCUSSION}

Our results indicate that NWHI fishes and invertebrates, grouped by closely related and ecologically equivalent species, can be separated into broad functional groups, within which individual species groups can be further distinguished from one another on the basis of their FA composition. FA trophic markers have long been recognized as efficient tools in studies of marine food webs (Sargent et al. 1989, Budge et al. 2002, 2006, Dalsgaard et al. 2003). Recent studies have demonstrated that FAs can be successfully used to elucidate feeding ecology and trophic relationships of marine fish (Drazen et al. 2009, Stowasser et al. 2009) and invertebrates (Silina \& Zhukova 2009, Spilmont et al. 2009). However, northern/temperate and abyssal marine ecosystems have been the focus of most research efforts, and FA data regarding trophic interactions in tropical marine ecosystems are scarce (reviewed by Dalsgaard et al. 2003). To our knowledge, our study is the first to employ FA analysis to investigate trophic and ecological relationships in a highly complex tropical reef ecosystem while also integrating such a large number of species in the analysis. Our database is comprised of a wide array of species, from different trophic levels/depths/habitats, which allows investigations to be conducted at various scales to ultimately provide a better picture of interactions occurring at the ecosystem level. Compared to their more temperate counterparts, most NWHI prey species contained very low levels of long-chain monounsaturated FA isomers (e.g. 20:1 and 22:1) which are typical of North Atlantic and North Pacific prey (Iverson 2009). They also exhibited much higher levels of n-6 polyunsaturated FAs, a characteristic previously reported in tropical marine prey species (Dalsgaard et al. 2003, Iverson 2009).

\section{Discriminant analysis among species groups}

DFA performed on the 47 species groups showed that diet played a primary role in discriminating among herbivorous fish, crustaceans reliant on heterotrophic 
benthos, and carnivorous fishes (Fig. 2). Planktivorous fishes were generally less well defined as an independent trophic group (except for the armorhead), consistent with the fact that they eat planktonic animals and larvae that feed directly on primary productivity; as such, their FA signature possesses attributes of both herbivorous and carnivorous diet. Cephalopods were spatially distinct from other groups but were also reliably differentiated from each other, despite their taxonomical relatedness. All deep-water species groups were scattered together in the lower right quadrant, while herbivores and planktivores were further separated from the crustaceans and cephalopods (Fig. 2). Overall, despite a relatively broad overlap, 27 of 47 groups were reasonably well classified at $>80 \%$ success. In many cases, misclassified individuals were classified into groups of closely related species and/or groups of species with similar diet and/or ecology. For example, box crabs were misclassified as other crustaceans (crabs and lobsters) which also feed on mollusks and benthic invertebrates.

The low levels of total body fat we found among most prey are common in species inhabiting a tropical environment, or an environment subjected to little fluctuation in food availability where there is no need to accumulate large energy reserves (Dalsgaard et al. 2003). However, the armorhead Pseudopentaceros wheeleri was composed of an astounding $27 \%$ fat. This can be explained by the life history of $P$. wheeleri, as juvenile armorheads undergo a 2+ year epipelagic pre-recruitment phase in the subarctic and transitional waters of the Northeast Pacific and Gulf of Alaska, building their fat reserves before returning to the Southern Emperor-Northern Hawaiian Ridge seamounts in the temperate central North Pacific to settle and begin maturation (Seki \& Somerton 1994, Humphreys 2000). Moreover, armorheads possessed high levels of $18: 1 \mathrm{n}-9(27 \%)$, a marker of animal production, which is consistent with a diet of planktonic fishes and invertebrates (Dalsgaard et al. 2003; see Table S3 in the supplement for detailed diet). Herbivores exhibited the highest levels of 16:0, an FA known to be more abundant in individuals feeding directly on primary production (Dalsgaard et al. 2003). Carnivores were lower in 20:5n-3 (eicosapentaenoic acid, EPA) relative to 22:6n-3 (docosahexaenoic acid, DHA), while the opposite situation was encountered in herbivores. This is in agreement with reports that EPA/DHA ratio values become smaller at higher trophic levels and thus can be used as an index of carnivory (Dalsgaard et al. 2003).

\section{Discriminant analyses within functional groups}

Classification success of a number of species groups increased upon conducting DFAs separately on each functional group. This indicates that finer scale variations in FA composition are detectable when a DFA is applied to groups sharing the same diet/ecology.

\section{Herbivores}

Herbivores play a key structural role in benthic coral reef communities (Hixon \& Brostoff 1996). They are a chief link between benthic primary productivity and higher trophic levels. Moreover, by consistently and differentially removing algae and/or exhibiting territorial behavior which prevents corallivore predation, herbivorous fish also promote local diversity on coral reefs (Hixon \& Brostoff 1996, Gochfeld 2010). Classification success was very high for the DFA conducted on the 5 groups of herbivores, and all individual groups had high proportions of individuals correctly classified (Fig. 3, Table 2). This indicates that angelfishes, parrotfishes, chubs, tang/surgeonfishes, and unicornfishes in this system can be accurately differentiated from one another on the basis of their FA composition. These results are consistent with previous findings that herbivorous reef fishes are selective feeders, and thus occupy narrower trophic niches (Cvitanovic \& Bellwood 2009, Hoey \& Bellwood 2009). For example, a study conducted on Lizard Island, Great Barrier Reef, has shown that a single species of unicornfish (Naso unicornis) was the dominant consumer of adult macroalgae of the genus Sargassum (Hoey \& Bellwood 2009). These feeding patterns are further understandable from a morphological and physiological standpoint, as some herbivorous reef fish species have evolved specialized digestive tracts and/or tolerance for algal chemical defense allowing them to feed on specific algae types (Stachowicz \& Hay 1999, Fox et al. 2009). All of the specimens in the herbivore group were collected from roughly the same depth range $(<20 \mathrm{~m})$, which contrasts with the range of specimens in the carnivore and crustacean groups; this could in part be responsible for preventing segregation of species along a depth gradient in this cluster.

\section{Planktivores}

Despite lacking spatial definition as a functional group on the original DFA analysis, the majority of planktivores were accurately classified on the basis of their FA composition. Heniochus diphreutes pennantfish were collected from lobster traps on bank summits, which is likely why they differed from planktivores collected at shallower depths. Melichthys niger triggerfish mostly feed on zooplankton but can also consume benthic algae (Froese \& Pauly 2009), which might ex- 
plain their high levels of 20:4n-6, a known marker of benthic productivity. While the proportion of correctly classified chromis/dascyllus individuals increased substantially in the within-planktivore DFA (Table 2), this group still had the lowest classification success of all planktivores. However, misclassified individuals were mostly classified as sergeants, another group of planktivores exhibiting similar foraging ecology (see Table S3 in the supplement). This indicates potential overlap in FA composition among these species.

\section{Carnivores}

Trophic relationships become less clear with increasing trophic levels as the FA signatures of consumers may originate from a greater variety of dietary sources (Dalsgaard et al. 2003, Iverson 2009). Examining trophic relations in carnivores, omnivores, and piscivores thus becomes more complex as our within-carnivores DFA illustrates. The effect on FA composition in species that feed in deep water was noticeable, as these groups (subphotic and slope) were separated from groups of species thriving at shallower depth (bank summits and reef flats) on the first 2 discriminant functions (Fig. 3). Classification success was highly variable among the 28 groups of carnivores. However, misclassifications generally occurred among closely related groups or groups with similar diet/ecology. Conger eels were mostly misclassified as moray eels, which have similar diets/habitat, or as cryptic benthic carnivores, which possess the same burrowing habits (Table 2; Table S3 in the supplement). Parupeneus goatfish were most commonly misclassified as sandperch and scorpionfish, with all 3 groups possessing both overlapping depth range and diets (benthic crustaceans; Table S3). Knife/razorfish were mostly misclassified as other burrowing or sand dwelling species such as Parupeneus goatfish, who probe the sand with their barbels to find benthic invertebrates.

The butterfly/forcepfish (Chaetodontidae) were spatially isolated from all other groups of carnivores. Chaetodontids encompass $61 \%$ of all corallivorous reef fish species (Bellwood et al. 2010). Among all species groups analyzed, the butterfly/forcepfish were the only group which included fish primarily feeding on live corals (e.g. Chaetodon multicinctus, C. ornatissimus, C. quadrimaculatus), and this group appeared to have a more distinct FA composition relative to all other carnivores.

\section{Crustaceans}

High proportions of correctly classified individuals (Table 2) for shrimps, swimming crabs, and slipper lobsters indicate that these groups/species of crusta- ceans can be readily distinguished by their FA signatures. Furthermore, the spatial distribution of groups/ species in the crustacean DFA (Fig. 3) suggested an influence of depth on FA signatures in species thriving in deep water, as the subphotic shrimps clearly separated from the other crustaceans. The remaining crab and lobster groups were more problematic; pebble crabs Carpilius convexus and spiny lobsters Panulirus marginatus were reasonably well classified, but the classification success of the box crabs remained poor (Table 2). Overlap in FA signatures among crabs and lobsters could be due to commonalities in diets, as these 2 groups of decapods reportedly feed on a mixture of mollusks, snails, and other benthic invertebrates (Table S3 in the supplement).

\section{Cephalopods}

Cephalopods associated together in the hierarchical cluster analysis, but separated more distinctly on the DFA performed on the 47 groups. Thus, despite their taxonomical relatedness, other factors such as diet and ecology have a great effect on their FA composition. Squids and octopuses were found to have characteristic FA compositions, and both were low in fat (on average $1.4 \%$ ). Some authors have suggested that findings of low total lipid content in squid are erroneous, and argued that these values must be derived from using partial versus whole specimens for lipid extraction (Phillips et al. 2002). However, that is not the case in our study, nor in some other analyses of whole cephalopods (e.g. Kirsch et al. 1998, Iverson et al. 2002).

On average, octopuses and squids exhibited noticeably higher levels of 22:6n-3 relative to herbivores, planktivores, carnivores, and crustaceans (Table S4 in the supplement), which has been found previously in the NWHI as well as other marine ecosystems (e.g. Goodman-Lowe et al. 1999, Budge et al. 2002, Iverson et al. 2002). Octopuses were sampled from shallow reef and bank depths $(<40 \mathrm{~m})$ and were more closely associated with prey that depend on the benthic productivity of the algal beds. Markers of benthic productivity (e.g. high levels of 20:4n-6) obtained through a diet of filter-feeding mollusks and other benthic invertebrates which feed directly on primary production are strongly conserved in octopuses. Contrastingly, prey base surveys found squid Sthenoteuthis oualaniensis at subphotic depths, and they were more closely associated with heterotrophs that rely much more on the detrital food web. The diet of $S$. oualaniensis reportedly consists mostly of myctophid fishes and other cephalopods (Parry 2006). Myctophids are pelagic fish primarily feeding on planktonic crustaceans (Shreeve et al. 2009). Marked differences in dietary sources among the 2 groups of cephalopods are thus reflected at the level of their FA signature. 


\section{Variations among ecological subsystems}

Results of DFAs of the 47 groups, of the carnivores, and of the crustaceans demonstrated that deep-water species in the NWHI had distinctive FA characteristics. In general, species living at subphotic depths (301 to $500 \mathrm{~m}$ ) or on the slope (51 to $300 \mathrm{~m}$ ) exhibited higher levels of 18:1n-9. Deep-water species groups readily distinguishable on the basis of their FA composition included armorheads, beardfish, cutthroat/snake eels, squirrelfish snappers, pink snappers, flower snappers, shrimps, and duckbills. This interesting pattern should be addressed in future analyses.

\section{CONCLUSIONS}

Our study clearly demonstrates that despite some existing overlap among FA signatures, differences in the FA composition of diverse fish and invertebrate species inhabiting the NWHI allows groups of closely related and ecologically similar species to be characterized. These differences in FA content primarily reflect diet, which can also be related to the habitat and ecology of these species. These results are promising, as they demonstrate that in spite of tremendous diversity, FA analyses could improve our understanding of the complex network of interactions structuring tropical coral reef ecosystems. Our findings also provide the foundation for using the same species groups/FAs in QFASA simulations and diet estimation of a key top predator in this ecosystem, the endangered Hawaiian monk seal. Moreover, the patterns identified in the prey community model will enhance the resolution at which use of the prey base by monk seals can be evaluated, which in turn will be useful in determining seal survivorship limitations in conjunction with tagging and diving studies. Future studies of the prey base should focus on increasing the resolution of these analyses by investigating differences in FA patterns among individual species, and incorporating a higher number of FAs in the analyses, as well as evaluating the effects of species misclassifications in actual estimates of monk seal diets.

Acknowledgements. We thank G. A. Antonelis, C. Littnan, and J. Baker from the Pacific Islands Fisheries Science Center (PIFSC) Protected Species Division for their extensive contributions to sample collection and research. We are grateful to S. Lang and members of the Iverson Lab at Dalhousie for assistance with sample processing and lab analyses and to W. Blanchard for statistical advice. We also thank W. Blanchard, S. Lang, and H. Smith for insightful comments on an earlier version of the manuscript. Financial support was provided by the National Oceanic and Atmospheric Administration (NOAA; US Department of Commerce), the PIFSC Protected
Species Division, Natural Sciences and Engineering Research Council (NSERC) Canada research and equipment grants to S.J.I., and a Fonds Québécois de la Recherche sur la Nature et les Technologies (FQRNT) fellowship to J.P.

\section{LITERATURE CITED}

Beck CA, Rea LD, Iverson SJ, Kennish JM, Pitcher KW, Fadely BS (2007) Blubber fatty acid profiles reveal regional, seasonal, age-class and sex differences in the diet of young Stellar sea lions in Alaska. Mar Ecol Prog Ser 338:269-280

> Bellwood DR, Klaten S, Cowman PF, Pratchett MS, Konow N, van Herwerden L (2010) Evolutionary history of the butterflyfishes (f: Chaetodontidae) and the rise of coral feeding fishes. J Evol Biol 23:335-349

> Budge SM, Iverson SJ, Bowen WD, Ackman RG (2002) Among- and within-species variability in fatty acid signatures of marine fish and invertebrates on the Scotian Shelf, Georges Bank, and southern Gulf of St. Lawrence. Can J Fish Aquat Sci 59:886-898

> Budge SM, Iverson SJ, Koopman HN (2006) Studying trophic ecology in marine ecosystems using fatty acids: a primer on analysis and interpretation. Mar Mamm Sci 22:759-801

Coffman M, Kim K (2009) The economic impacts of banning commercial bottomfish fishing in the Northwestern Hawaiian Islands. Ocean Coast Manag 52:166-172

Cvitanovic C, Bellwood DR (2009) Local variation in herbivore feeding activity on an inshore reef on the Great Barrier Reef. Coral Reefs 28:127-133

> Dalsgaard J, St John M (2004) Fatty acid biomarkers: validation of food web and trophic markers using ${ }^{13} \mathrm{C}$-labelled fatty acids in juvenile sandeel (Ammodytes tobianus). Can J Fish Aquat Sci 61:1671-1680

> Dalsgaard J, St. John M, Kattner G, Müller-Navarra D, Hagen W (2003) Fatty acid trophic markers in the pelagic marine environment. Adv Mar Biol 46:225-340

> Deagle BE, Tollit DJ, Jarman SN, Hindell MA, Trites AW, Gales NJ (2005) Molecular scatology as a tool to study diet: analysis of prey DNA in scats from captive Steller sea lions. Mol Ecol 14:1831-1842

Drazen JC, Phleger CF, Guest MA, Nichols PD (2009) Lipid composition and diet inferences in abyssal macrourids of the eastern North Pacific. Mar Ecol Prog Ser 387:1-14

Folch J, Lees M, Stanley GHS (1957) A simple method for the isolation and purification of total lipides from animal tissues. J Biol Chem 226:497-509

Fox RJ, Sunderland TL, Hoey AS, Bellwood DR (2009) Estimating ecosystem function: contrasting roles of closely related herbivorous rabbitfishes (Siganidae) on coral reefs. Mar Ecol Prog Ser 385:261-269

Friedlander AM, DeMartini EE (2002) Contrasts in density, size, and biomass of reef fishes between the northwestern and the main Hawaiian islands: the effects of fishing down apex predators. Mar Ecol Prog Ser 230:253-264

Froese R, Pauly D (eds) (2009) FishBase. www.fishbase.org

Gochfeld DJ (2010) Territorial damselfishes facilitate survival of corals by providing an associational defense against predators. Mar Ecol Prog Ser 398:137-148

> Goodman-Lowe GD (1998) Diet of the Hawaiian monk seal (Monachus schauinslandi) from the Northwestern Hawaiian islands during 1991 to 1994. Mar Biol 132:535-546

Goodman-Lowe GD, Carpenter JR, Atkinson S, Ako H (1999) Nutrient, fatty acid, amino acid, and mineral analysis of natural prey of the Hawaiian monk seal, Monachus schauinslandi. Comp Biochem Physiol A 123:137-146 
Hixon MA, Brostoff WN (1996) Succession and herbivory: effects of differential fish grazing on Hawaiian coral-reef algae. Ecol Monogr 66:67-90

Hobson ES (1974) Feeding relationships of teleostean fishes on coral reefs in Kona, Hawaii. Fish Bull 72:915-1031

> Hoey AS, Bellwood DR (2009) Limited functional redundancy in a high diversity system: single species dominates key ecological process on coral reefs. Ecosystems 12: 1316-1328

Hoover JP (1998) Hawai'i's sea creatures, a guide to Hawai'i's marine invertebrates. Mutual Publishing, Honolulu, HI

> Humphreys RLJ (2000) Otolith-based assessment of recruitment variation in a North Pacific seamount population of armorhead Pseudopentaceros wheeleri. Mar Ecol Prog Ser 204:213-223

Iverson SJ (2009) Tracing aquatic food webs using fatty acids: from qualitative indicators to quantitative determination. In: Arts MT, Brett MT, Kainz M (eds) Lipids in aquatic ecosystems. Springer-Verlag, New York, NY, p 281-307

Iverson SJ, McDonald JE, Smith LK (2001) Changes in the diet of free-ranging black bears in years of contrasting food availability revealed through milk fatty acids. Can J Zool 79:2268-2279

Iverson SJ, Frost KJ, Lang SLC (2002) Fat content and fatty acid composition of forage fish and invertebrates in Prince William Sound, Alaska: factors contributing to among and within species variability. Mar Ecol Prog Ser 241:161-181

Iverson SJ, Field C, Bowen WD, Blanchard W (2004) Quantitative fatty acid signature analysis: a new method of estimating predator diets. Ecol Monogr 74:211-235

Iverson SJ, Stirling I, Lang SLC (2006) Spatial and temporal variation in the diets of polar bears across the Canadian arctic: indicators of changes in prey populations and environment. In: Boyd IL, Wanless S, Camphuysen CJ (eds) Top predators in marine ecosystems. Cambridge University Press, Cambridge

- Iverson SJ, Springer AM, Kitayski AS (2007) Seabirds as indicators of food web structure and ecosystem variability: qualitative and quantitative diet analyses using fatty acids. Mar Ecol Prog Ser 352:235-244

Kirsch PE, Iverson SJ, Bowen WD, Kerr SR, Ackman RG (1998) Dietary effects on the fatty acid signature of whole Atlantic cod (Gadus morhua). Can J Fish Aquat Sci 55:1378-1386

Kittinger JN, Duin KN, Wilcox BA (2010) Commercial fishing, conservation and compatibility in the Northwestern Hawaiian Islands. Mar Policy 34:208-217

Maragos J, Gulko D (2002) Coral reef ecosystems of the Northwestern Hawaiian Islands: interim results emphasizing the 2000 surveys. U.S. Fish and Wildlife Service and the Hawai'i Department of Land and Natural Resources, Honolulu, HI

Moffitt RB, Parrish FA (1992) An assessment of the exploitable biomass of Heterocarpus laevignatus in the main Hawaiian Islands. Part 2: Observations from a submersible. Fish Bull 90:476-482

> Nordstrom CA, Wilson LJ, Iverson SJ, Tollit DJ (2008) Evaluating quantitative fatty acid signature analysis (QFASA) using harbour seals Phoca vitulina richardsi in captive feeding studies. Mar Ecol Prog Ser 360:245-263

Palomares MLD, Pauly D (eds) (2010) SeaLifeBase. www. sealifebase.org

Parrish FA, Abernathy K (2006) Movements of monk seals relative to ecological depth zones in the lower Northwestern Hawaiian islands. Atoll Res Bull 543:115-130

Parrish FA, Boland RC (2004) Habitat and reef-fish assemblages of banks in the Northwestern Hawaiian Islands. Mar Biol 144:1065-1073

Editorial responsibility: Michael Castellini,

Fairbanks, Alaska, USA
Parrish FA, Craig MP, Ragen TJ, Marshall GJ, Buhleier BM (2000) Identifying diurnal foraging habitat of endangered Hawaiian monk seals using seal-mounted video camera. Mar Mamm Sci 16:392-412

> Parrish FA, Abernathy K, Marshall GJ, Buhleier BM (2002) Hawaiian monk seals (Monachus schauinslandi) foraging in deep-water coral beds. Mar Mamm Sci 18:244-258

Parrish JD (1989) Fish communities of interacting shallowwater habitats in tropical oceanic regions. Mar Ecol Prog Ser 58:143-160

Parrish JD, Norris JE, Callahan MW, Callahan JK, Magarifuji EJ, Schroeder RE (1986) Piscivory in a coral reef fish community In: Simenstad CA, Cailliet GM (eds) Contemporary studies on fish feeding, Vol 7. Junk, Dordrecht, p 285-298

$>$ Parry M (2006) Feeding behavior of two ommastrephid squids Ommastrephes bartramii and Sthenotheutis oualaniensis off Hawaii. Mar Ecol Prog Ser 318:229-235

Phillips KL, Nichols PD, Jackson GD (2002) Lipid and fatty acid composition of the mantle and digestive gland of four Southern Ocean squid species: implication for food-web studies. Antarct Sci 14:212-220

Polovina JJ, Mitchum GT (1992) Variability in spiny lobster Panulirus marginatus recruitment and sea level in the Northwestern Hawaiian Islands. Fish Bull 90:483-493

Ragen TJ, Lavigne DM (1999) The Hawaiian monk seal: biology of an endangered species. In: Twiss JRJ, Reeves RR (eds) Conservation and management of marine mammals. Smithsonian Institution Press, Washington, DC, p 224-245

Randall JE (1996) Shore fishes of Hawai'i. University of Hawaii Press, Honolulu, HI

Sargent JR, Henderson RJ, Tocher DR (1989) The lipids. In: Halver JE (ed) Fish nutrition. Academic Press, San Diego, CA, p 153-218

Seki MP, Somerton DA (1994) Feeding ecology and daily ration of the pelagic armorhead, Pseudopentaceros wheeleri, at Southeast Hancock Seamount. Environ Biol Fishes 39:73-84

Shreeve RS, Collins MA, Tarling GA, Main CE, Ward P, Johnston NM (2009) Feeding ecology of myctophid fishes in the northern Scotia Sea. Mar Ecol Prog Ser 386:221-236

Silina AV, Zhukova NV (2009) Topical and trophic relationships in a boring polychaete-scallop association: fatty acid biomarker approach. Mar Ecol Prog Ser 394:125-136

Spilmont N, Meziane T, Seuront L, Welsh DT (2009) Identification of the food source of sympatric ghost shrimp (Trypaea australiensis) and soldier crab (Mictyris longicarpus) population using a lipid biomarker, dual stable isotope approach. Austral Ecol 34:878-888

Stachowicz JJ, Hay ME (1999) Mutualism and coral persistence: the role of herbivore resistance to algal chemical defense. Ecology 80:2085-2101

Steele MA (1996) Effects of predators on reef fishes: separating cage artifacts from effects of predation. J Exp Mar Biol Ecol 198:249-267

> Stowasser G, Pond DW, Collins MA (2009) Using fatty acid analysis to elucidate the feeding habits of Southern Ocean mesopelagic fish. Mar Biol 156:2289-2302

Thiemann GW, Iverson SJ, Stirling I (2008) Polar bear diets and Arctic marine food webs: insights from fatty acid analyses. Ecol Monogr 78:591-613

> Tucker S, Bowen WD, Iverson SJ, Blanchard W, Stenson GB (2009) Sources of variation in diets of harp (Pagophilus groenlandicus) and hooded (Cystophora cristata) seals estimated from quantitative fatty acid signature analysis (QFASA). Mar Ecol Prog Ser 384:287-302

Wood R (1999) Reef evolution. Oxford University Press, New York, NY

Submitted: April 25, 2010; Accepted: September 7, 2010

Proofs received from author(s): October 29, 2010 